\title{
HEPATITIS B AND HEPATITIS C SEROPOSITIVE SURGICAL CASES AND ITS IMPACT ON PERIOPERATIVE BLOOD TRANSFUSION
}

\author{
Mobeen Ikram, Saira Mahboob*, Rizwan Yusuf \\ Combined Military Hospital Okara/National University of Medical Sciences (NUMS) Pakistan, *Pakistan Naval Ship Shifa Hospital, Karachi Pakistan
}

\begin{abstract}
Objective: To evaluate the frequency of Hepatitis B and Hepatitis C on our surgical patients and its impact on operation theater delay, change of anesthesia plan and requirement of perioperative blood and blood products transfusion.

Study Design: Cross sectional, analytical study.

Place and Duration of Study: Department of Anesthesiology, Combined Military Hospital, Okara, from Apr to Sep 2019.

Methodology: After the approval of the hospital ethical review committee, 154 patients with either Hepatitis B or Hepatitis C undergoing various surgeries were included in our study. Data was analyzed using SPSS-20.

Results: The overall frequency of chronic liver disease was $154(4.71 \%)$. A total of $23(0.70 \%)$ were found to be seropositive as viral Hepatitis B and $127(3.88 \%)$ as Hepatitis C; whereas $4(0.12 \%)$ patients were diagnosed to have both virus serology positive. There was mean delay of $26.2 \pm 8.29$ minutes in $78(52 \%)$ patients. The anesthetist had to change the plan of anesthesia for only $1(0.7 \%)$ patient. There was also no difference in frequency of change of anesthesia plan $(p=0.35)$; delay in surgery $(p=0.16)$ and blood transfusion between the patients with Hepatitis B or Hepatitis C infection $(p=0.72)$.

Conclusion: The frequency of Hepatitis B and Hepatitis C was lower $(4.71 \%)$ in our surgical patients with no effect of Hepatitis B and Hepatitis C on blood loss, peri-operative transfusion, delay in surgery or change in anesthesia plan.
\end{abstract}

Keywords: Blood transfusion, Delay in surgery, Seropositive Hepatitis B, Seropositive Hepatitis C.

How to Cite This Article: Ikram M, Mahboob S, Yusuf R. Hepatitis B and Hepatitis C Seropositive Surgical Cases and Its Impact on Perioperative Blood Transfusion. Pak Armed Forces Med J 2021; 71(5): 1594-1597. doi: https://doi.org/10.51253/pafmj.v71i5.4462

This is an Open Access article distributed under the terms of the Creative Commons Attribution License (https://creativecommons.org/licenses/by-nc/4.0/), which permits unrestricted use, distribution, and reproduction in any medium, provided the original work is properly cited.

\section{INTRODUCTION}

World-wide, cirrhosis is the eleventh most common cause of death and along with liver cancer accounts for $3.5 \%$ of deaths globally. ${ }^{1}$ In Pakistan, prevalence of Hepatitis B (HBV) is $10 \%$ and that of Hepatitis C (HBC) is $4-10 \% .^{2}$ Masood et al, reported co-infection with both viruses in $31(1.5 \%)$. A study in a tertiary care hospital of Rawalpindi reported a prevalence of Hepatitis B and Hepatitis $C$ in surgical patients is $41(0.5 \%)$. Due to high transmission risk of Hepatitis B $(30 \%)$ and Hepatitis C (2-10\%) after an accidental needle prick and higher incidence in general population, screening for Hepatitis B and Hepatitis C should be a routine preoperative investigation. ${ }^{5,6}$ Reuse of needles, unscreened blood transfusion, use of improperly sterilized instruments during surgical, obstetrical and dental procedures, unsafe sex, barbers and body piercing are some of the common causes of transmission of viral hepatitis., ${ }^{7,8}$

Various studies have been done on the impact of chronic liver disease on perioperative morbidity and mortality. Child-pugh criteria and model for end stage liver disease (MELD) score are the most commonly used tool for assessing the severity of liver disease. ${ }^{9}$

Correspondence: Dr Mobeen Ikram, Classified Anaesthetist, Combined Military Hospital, Okara Pakistan

Received: 11 Jun 2020; revision received: 01 Sep 2020; accepted: 03 Sep 2020
Child-Pugh criteria require laboratory as well as clinical parameters; whereas MELD score requires laboratory investigation. In a resource poor country with deficient medical infrastructure combined with poor affordability of test, laboratory investigations may not always be possible according to international standards. In such a medical setting of a developing country, anesthetist at times have to formulate and follow local guidelines that serve to maintain a balance between patient safety and economic impact of healthcare. At our present institute, we have standing operating procedure that all patients reporting to operation theatre for any type of surgery will have hepatitis screening done before surgery and all those patients who will be positive for Hepatitis B and Hepatitis C will have their liver functions and coagulation profile done, so that it will be helpful during peri-operative period for choice of anesthesia and for arranging blood and blood products. The purpose of our study was to evaluate the frequency of Hepatitis B and Hepatitis C on our surgical patients and its impact on delay in surgery, anesthesia plan and requirement of perioperative blood and blood products transfusion.

\section{METHODOLOGY}

This cross-sectional analytical study was conducted at Combined Military Hospital Okara, from 
April to September 2019 after the approval of hospital ethics committee. World Health Organization (WHO) sample size calculator was used to calculate a sample size of 130 patients with expected frequency of $9.33 \%$ of positive Hepatitis B serology. ${ }^{10}$

Inclusion Critria: Patients of both genders who were greater than 18 years age, American Society of Anesthesiologist physical status $\leq \mathrm{III}$ who were planned for elective surgeries were included in our study by convenience sampling.

Exclusion Critria: Patients with ongoing bleeding, undergoing emergency surgeries or unwilling to participate were excluded from our study.

Most of pre-operative preparation was being done by the concerned surgical specialist with patients being referred to preanesthesia assessment (PAA) clinic by surgeon on case-to-case basis. The pre-anesthesia assessment by the anesthetist was done as per institute protocol either at PAA clinic or in the operating table and no changes were made for our study. A clinical diagnosis of decompensated liver disease was made in some cases on the basis of signs and symptoms of advanced decompensated liver disease like hematemesis, melena, ascites or laboratory investigations available with patient. The data was collected on a predesigned proforma and filled by a first year resident anesthesia. The estimation of blood loss was done by a consultant anesthetist. Our outcomes were: frequency of Hepatitis B and Hepatitis C sero-positive cases with current liver function tests and previous treatment taken; delay in elective surgery; comparison of intra-operative blood loss and perioperative blood transfusion in seropositive cases.

Data was analyzed using SPSS-22. Descriptive variables were presented as mean \pm SD and independent sample t-test was used to calculate significance. Qualitative variables presented as frequency and percentage and chi-square used to test significance. The $p$ value of $\leq 0.05$ was taken as significant.

\section{RESULTS}

The overall frequency of seropositive $\mathrm{HBV}$ and HCV cases was $154(4.71 \%)$. A total of $127(3.88 \%)$ as Hepatitis C; $23(0.70 \%)$ were found to be seropositive as viral Hepatitis B and; whereas $4(0.12 \%)$ patients were diagnosed to have both virus serology positive on ELISA. Finally, 150 patients were included in final analysis of our study. The mean age of the study population was $37.92 \pm 13.95$ years. Most of the patients were female 111 (74\%). Liver Function Tests (LFT) were performed in all patients with chronic liver disease but we were able to record data: serum bilirubin in 77 (51.3\%); ALT 83 (55.3\%); alkaline phosphatase 77 (51.3\%); prothrombin time (PT) 113 (75.3\%); partial thromboplastin time (PTTK) in 110 (73.3\%) and albumin level in $9(6 \%)$ at first presentation with anesthetist. The mean values of LFT and coagulation profile are shown in Table-I.

The diagnosis of viral liver disease was made by immune-chromatography (ICT) in most cases 74 (49.3\%) followed by ELISA (enzyme linked immunosorbent assay) test in 70 (46.7\%) and PCR (Polymerase

Table-I: Liver function test, coagulation profile and albumin of study group.

\begin{tabular}{l|c}
\hline Liver Function Test & Mean \pm SD \\
\hline Serum Bilirubin $(\mathrm{mmol} / \mathrm{dL})$ & $11.5 \pm 3.86$ \\
\hline Serum ALT (unit/liter) & $50.49 \pm 28.34$ \\
\hline $\begin{array}{l}\text { Serum Alkaline Phosphatase } \\
\text { (unit /liter) }\end{array}$ & $206.24 \pm 67.59$ \\
\hline Prothrombin time (seconds) & $14.74 / 14$ (control) \pm 1.5 \\
\hline $\begin{array}{l}\text { Activated prothrombin time } \\
\text { (seconds) }\end{array}$ & $33.96 / 32$ (control) \pm 3.84 \\
\hline Serum Albumin (g/dL) & $32.11 \pm 3.95$ \\
\hline
\end{tabular}

Chain Reaction) 5 (3.3\%). The duration of disease is shown in Figure-1, 44 (29.3\%) patients had been treated for chronic liver disease as shown in Figure-2.

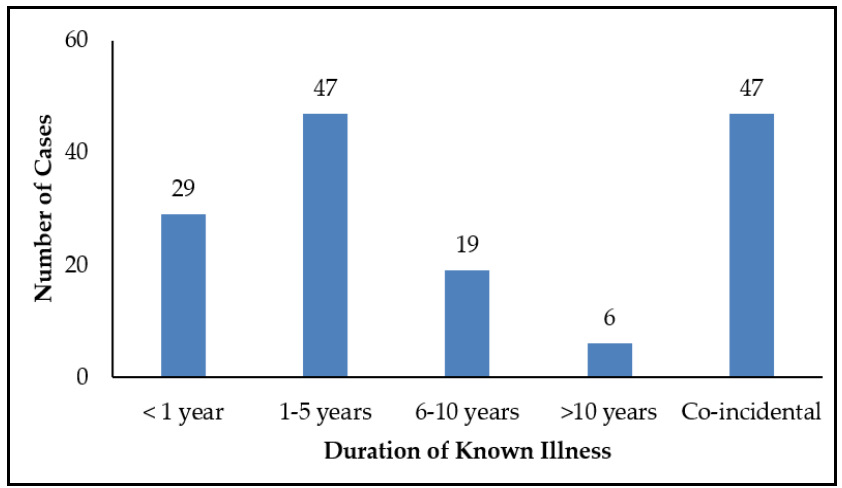

Figure-I: Duration of known liver disease in study population.

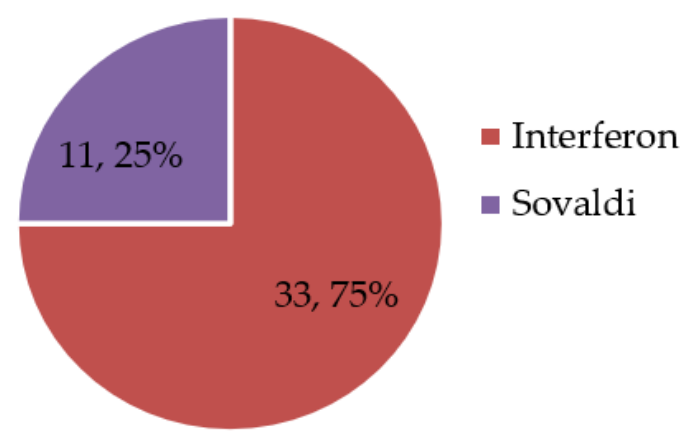

Figure-II: Treatment taken by patients for chronic liver disease. 
The pre-anesthesia assessment was done in preanesthesia clinic in only $52(34.7 \%)$ whereas, patient was assessed by anesthetist on table in 98 (65.3\%) cases, $93(62 \%)$ patients had no signs of decompensation; whereas $5(3.3 \%)$ had one or more signs of decompensated liver disease during pre-operative workup.

There was a mean delay of $26.2 \pm 8.29$ minutes in 78 (52\%) patients that is attributable to Hepatitis B and Hepatitis $C$ seropositive cases. The anesthetist had to change the plan of anesthesia for only $1(0.7 \%)$ patient due to liver disease. The correlation in estimated blood loss during surgeries and either Hepatitis B or Hepatitis $C$ sero-positive cases; frequency of change of anesthesia plan; delay in surgery and blood transfusion between the patients with Hepatitis B or Hepatitis C infection is shown in Table-II.

\begin{tabular}{|c|c|c|c|c|}
\hline \multicolumn{2}{|c|}{ Variable } & Hepatitis B & Hepatitis C & $p$-value \\
\hline \multirow{2}{*}{$\begin{array}{l}\text { Intra- } \\
\text { Operative } \\
\text { Blood Loss }\end{array}$} & $<500 \mathrm{ml}$ & $15(10 \%)$ & $93(62 \%)$ & \multirow[b]{2}{*}{0.825} \\
\hline & $>500 \mathrm{ml}$ & $4(2.7 \%)$ & $18(12 \%)$ & \\
\hline \multirow{2}{*}{$\begin{array}{l}\text { Intra- } \\
\text { Operative } \\
\text { Transfusion }\end{array}$} & Yes & $3(2 \%)$ & $1(0.7 \%)$ & \multirow[b]{2}{*}{0.750} \\
\hline & No & $124(82.7 \%)$ & $22(14.7 \%)$ & \\
\hline \multirow{2}{*}{$\begin{array}{l}\text { Delay in } \\
\text { Surgery }\end{array}$} & Yes & $2(1.3 \%)$ & $(0.7 \%)$ & \multirow{2}{*}{0.618} \\
\hline & No & $115(83.4 \%)$ & $22(14.7 \%)$ & \\
\hline \multirow{2}{*}{$\begin{array}{l}\text { Change in } \\
\text { Anesthesia } \\
\text { Plan }\end{array}$} & Yes & $1(0.7 \%)$ & $126(84 \%)$ & \multirow[b]{2}{*}{0.138} \\
\hline & No & - & $23(11.3 \%)$ & \\
\hline $\begin{array}{l}\text { Delay in } \\
\text { Surgery } \\
\text { (minutes) }\end{array}$ & $\begin{array}{l}\text { Mean } \pm \\
\text { SD }\end{array}$ & $26.8 \pm 7.52$ & $26.1 \pm 8.41$ & 0.62 \\
\hline
\end{tabular}

\section{DISCUSSION}

Our study showed no difference in perioperative requirement of blood or blood products; change in anesthesia plan or delay in surgery due to Hepatitis B and Hepatitis $C$ seropositive cases. A meta-analysis by Ali et al reported the prevalence of Hepatitis B antigen as $2.4 \%(1.4-11 \%)$ and that of Hepatitis C antibody form 3\% (0.3-31.9\%) in Pakistan. ${ }^{11}$ However, our study showed a frequency of $3.88 \%$ of Hepatitis C and $0.7 \%$ frequency of Hepatitis B in surgical patients.

Memon et al, reported a higher incidence of Hepatitis B surface antigen ( $\mathrm{HbsAg}$ ) in 3.61\% and Hepatitis $\mathrm{C}$ antibody (anti-HCV) in $12.8 \%$ with equal frequency in both genders. In their study, both were more common in males. ${ }^{12}$ Similarly, Tahir et al, reported a higher incidence of $2.62 \%$ of Hepatitis B but a lower incidence of Hepatitis $C$ in $6.17 \%$ in their patients undergoing cataract surgery. They reported a higher incidence in females $(6.32 \%$ anti-HCV and $3.44 \% \mathrm{HbsAg})$. All of their patients were asymptomatic carrier of the disease. 13 Wazir et al, reported a frequency of $2.5 \%$ of Hepatitis B and Hepatitis C sero-positive patients with a male, female ratio of $1.73: 1$ with $46.15 \%$ of patients in their third decade of life. ${ }^{14} \mathrm{We}$ have reported mean age of our sero-positive patients to be 37.92 years \pm 13.95 with most of them females (74\%). Lohano et al reported an incidence of $2.54 \%$ of Hepatitis B and $12.81 \%$ of Hepatitis $C$ at an eye hospital in Hyderabad. Most were more than 50 years (46.4\% Hepatitis B and 55.3\% in Hepatitis C) with females more commonly effected. They performed immune-chromotography (ICT) as screening test and confirmed by ELISA. They recommended PCR for quantitative and qualitative detection of viral gene. ${ }^{15}$ Screening was done most commonly by ICT (if time constrains required early surgery) while ELISA was also used commonly for screening in our study.

Multiple studies have been done on prevalence and risk factors for complications of Hepatitis $\mathrm{B}$ and Hepatitis $C$ in the perioperative period. However, according to authors' knowledge there are no published studies locally that compare seropositive Hepatitis B or Hepatitis $C$ regarding perioperative blood transfusion or surgical delays. We conducted this study with the aim to evaluate their frequency in surgical patients with the aim on peri-operative blood transfusion and surgical delays in elective list. Although intra-operative blood loss is dependent on multiple factors including patient factors like coagulopathies, platelet dysfunction or deficiency, disseminated intravascular coagulopathy (DIC) as well as surgical factors like blood vessel injury. Yamamoto et al, studied hepatectomy for cancer; and reported thrombocytopenia, elevated alpha-fetoprotein levels, increased tumor size and major hepatectomy as indicators for intraoperative blood transfusions. Our finding also support that there is no correlation between Hepatitis B or Hepatitis C seropositive cases and perioperative blood loss or blood product transfusion. With these findings, we were able to create a policy where mere presence of seropositive liver disease does not require arranging blood or blood product. Thus reducing the workload and economic burden to patient and laboratory.

There is increased perioperative risk of exposure/ transmission of Hepatitis B and Hepatitis C to healthcare workers due to accidental cuts, needle stick injury, exposure to blood and body secretion. ${ }^{17,18}$ Universal precautions are recommended to prevent nosocomial infections. In addition, Hepatitis B antigen or Hepatitis 
C seropositive cases are conducted at the end of our elective list to avoid unnecessary delays in completion of list. These delays may be due to lack of availability of inadequate pre-operative preparation, lack of proper laboratory investigations or blood products. By a close collaboration between the surgical teams and anesthetist, we were able to keep the delay limited to less than 30. Our institute is a secondary level hospital with no hepatologist or gastroenteterologist posted there. To improve the patient safety and outcomes, all perioperative patients showing signs of decompensation were managed by our medical specialist and referred to a tertiary care setup for optimization prior to surgery.

\section{LIMITATION OF STUDY}

We could not study long-term mortality or morbidity as a variable and we cannot comment of validity of our results on long-term outcomes. The various surgeries were done by different surgeon and may have resulted in varied blood loss for same procedure.

\section{CONLCUSION}

The frequency of Hepatitis B and Hepatitis C was lower $(4.71 \%)$ in our surgical patients with no effect of Hepatitis B and Hepatitis $\mathrm{C}$ on blood loss, peri-operative transfusion, delay in surgery or change in anesthesia plan.

\section{Conflict of Interest: None.}

\section{Authors' Contribution}

MI: Literature review, SM: Statistical analysis, manuscript editing, RY: Statistical review.

\section{REFERENCES}

1. Asrani SK, devabhavi H, Eaton J, Kamath PS. Burden of liver disease in the world. J Hepatol 2019; 70(1): 151-171.

2. Tahir MA, Cheema A, Tareen S. Frequency of Hepatitis-B and C in patients undergoing cataract surgery in a tertiary care centre. Pak J Med Sci 2015; 31(4): 895-898.
3. Masood Z, Jawaid M. Screening for hepatitis B \& C: A routine preoperative investigation? Pak J Med Sci 2005; 21(4): 455-459.

4. Ahmed N, Naseem K, Burki A. Prevalence of hepatitis B and C in surgical patients, $\mathrm{CMH}$ Rawalpindi. Pak Armed Forces Med J 2018; 68(4): 953-57.

5. Sable S, Nagral A. Hepatitis B and the surgeon. Hep B Annual 2011; 8(1): 17-31.

6. William DF. Hepatitis C and the surgeon. Can J Surg 2013; 56(2): 80-81.

7. Akhtar H, Badsha Y. Prevalence of hepatitis B and hepatitis C Virus infections among male to female (MFT) transgenders in Rawalpindi (Pakistan). Adv. Life Sci 2018; 5(2): 46-55.

8. Yang S, Wang D, Zhang Y, Yu C, Ren J. Transmission of hepatitis $B$ and $C$ virus Infection through body piercing: a systematic review and meta-analysis. Med (Baltimore) 2015; 94(47): e1893.

9. Friedman LS. Surgery in patients with Liver Disease. Trans Am Clin Climat Assoc 2010; 121(4): 192-205.

10. Daudpota AQ, Soomro AW. Sero prevalence of hepatitis B and C in surgical patients. Pak J Med Sci 2008; 24(1): 483-484.

11. Ali SA, Donahue Rafe MJ. Hepatitis B and hepatitis C in Pakistan: prevalence and risk factors. Int J Inf Dis 2009; 13: 9-19.

12. Memon MR, Shaikh AA, Soomro AA, Arshad S, Shah QS. Frequency of hepatitis $B$ and $C$ in patients undergoing elective surgery. J Ayub Med Coll Abbottabad 2010; 22(2): 167-170.

13. Tahir MA, Cheema a, Tareen S. frequency of hepatitis B and C in patients undergoing cataract surgery in a tertiary care centre. Pak J Med Sci 2015; 31(4): 895-898.

14. Wazir S, Khan M, Ahmed T. frequency of hepatitis B and C in patients operated in oral and maxillofacial surgery unit-a hospital based study. Pak Oral Dental J 2016; 36(3): 364-367.

15. Lohano MK, Su L, Narsani AK, Jawed M, Naveed H. Frequency of hepatitis B surface antigen ( $\mathrm{HbsAg}$ ) and Hepatitis C antibody ( $\mathrm{HCVAb})$ seropositivity among preoperative elective surgery patients. BJMP 2016; 9(2): a918-a922.

16. Yamamoto $Y$, Ikoma H, Morimura R, Konishi H, Murayama $Y$, Komatsu A, et al. Predictive scoring system assessing the need for intraoperative blood tarnsfusion during hepatectomy for hepatocellular carcinoma. Antican Res 2014; 34(2): 313-318.

17. Sonal A and Kneteman N. Operating on a patient with hepatitis C. Can J Surg 2009; 52(4): 337-342.

18. Sable S, Nagral A. Hepatitis B and the surgeon. Hep B Annual [serial online] 2011; 8(2): 17-31. 